\title{
Structure and Electrochemical Hydrogen Storage Properties of as-Milled Mg-Ce-Ni-Al-Based Alloys
}

\author{
Yanghuan Zhang ${ }^{1,2} \cdot$ Zhenyang $\mathrm{Li}^{2} \cdot$ Wei Zhang ${ }^{1,2} \cdot$ Wengang $\mathrm{Bu}^{2} \cdot$ Yan $\mathrm{Qi}^{2} \cdot$ Shihai Guo ${ }^{2}$
}

Received: 9 June 2019 / Revised: 28 August 2019 / Published online: 6 January 2020

(C) The Chinese Society for Metals (CSM) and Springer-Verlag GmbH Germany, part of Springer Nature 2020

\begin{abstract}
At room temperature, crystalline $\mathrm{Mg}$-based alloys, including $\mathrm{Mg}_{2} \mathrm{Ni}, \mathrm{MgNi}, \mathrm{REMg} \mathrm{I}_{12}$ and $\mathrm{La}_{2} \mathrm{Mg}_{17}$, have been proved with weak electrochemical hydrogen storage performances. For improving their electrochemical property, the $\mathrm{Mg}$ is partially substituted by $\mathrm{Ce}$ in $\mathrm{Mg}-\mathrm{Ni}$-based alloys and the surface modification treatment is performed by mechanical coating Ni. Mechanical milling is utilized to synthesize the amorphous and nanocrystalline $\mathrm{Mg}_{1-x} \mathrm{Ce}_{x} \mathrm{Ni}_{0.9} \mathrm{Al}_{0.1}(x=0,0.02,0.04,0.06$, $0.08)+50 \mathrm{wt} \% \mathrm{Ni}$ hydrogen storage alloys. The effects made by Ce substitution and mechanical milling on the electrochemical hydrogen storage property and structure have been analyzed. It shows that the as-milled alloys electrochemically absorb and desorb hydrogen well at room temperature. The as-milled alloys, without any activation, can reach their maximal discharge capacities during first cycling. The maximal value of the 30-h-milled alloy depending on Ce content is $578.4 \mathrm{mAh} / \mathrm{g}$, while that of the $x=0.08$ alloy always grows when prolonging milling duration. The maximal discharge capacity augments from 337.4 to $521.2 \mathrm{mAh} / \mathrm{g}$ when milling duration grows from 5 to $30 \mathrm{~h}$. The cycle stability grows with increasing Ce content and milling duration. Concretely, the $S_{100}$ value augments from 55 to $82 \%$ for the alloy milled for $30 \mathrm{~h}$ with Ce content rising from 0 to 0.08 and from 66 to $82 \%$ when milling the $x=0.08$ alloy mechanically from 5 to $30 \mathrm{~h}$. The alloys' electrochemical dynamics parameters were measured as well which have maximum values depending on Ce content and keep growing up with milling duration extending.
\end{abstract}

Keywords $\mathrm{Mg}-\mathrm{Ni}$-based alloy $\cdot \mathrm{Ce}$ substituting $\mathrm{Mg} \cdot$ Surface modification $\cdot$ Mechanical milling $\cdot$ Electrochemical performance

\section{Introduction}

Human beings are facing two big challenges: the dwindled fossil fuel and accelerated greenhouse effect [1]. A project to limit fossil fuels wasting and reduce carbon dioxide emission is developing alternative energies, especially in vehicles as transport occupies $25 \%$ of worldwide entire energy consumption [2] and 23\% $\mathrm{CO}_{2}$ emission [3]. The government

Available online at http://link.springer.com/journal/40195.

Yanghuan Zhang

zhangyh59@sina.com

1 Key Laboratory of Integrated Exploitation of Baiyun Obo Multi-Metal Resources, Inner Mongolia University of Science and Technology, Baotou 014010, China

2 Department of Functional Material Research, Central Iron and Steel Research Institute, No. 76 Xueyuannan Road, Haidian District, Beijing 100081, China of China has already declared "The regulation of access of new energy automobile production enterprises and products" which pressed the Ni-MH battery to become an auxiliary power and promoted the progress of Ni-MH batteries, whereas innovation must be carried out to ameliorate the performance of Ni-MH batteries and save their costs to gain more recognition from consumers for the electric vehicle (EV) and hybrid electric vehicle (HEV).

Extensive researches have been done to study hydrogen storage systems based upon various metal hydrides. Many metal hydrides with application potential were found [4-8]. Particularly, Mg-based hydrogen storage alloys, which are utilized in negative electrode material in Ni-MH batteries, are regarded as a selected candidate and attract high attention now for the reasons of high capacity and low price [9-14]. The international symposium on metal hydrogen system fundamental and applications (MH2016) still concentrated on the research as well as the application of Mg-based hydrogen storage alloys. Nevertheless, some attempts to apply the 
Mg-based alloys were frustrated because of their extremely terrible electrochemical cycle steadiness and exceedingly inadequate discharge capacity at room temperature when they are applied as negative electrode materials [15]. Apparently, drastically improving the electrochemical properties of $\mathrm{Mg}$-based alloys is an enormous scientific challenge.

It is on the surface of alloys that $\mathrm{Mg}(\mathrm{OH})_{2}$ layers will form and grow during lectrochemical reaction process. In charge transfer and hydrogen diffusion reactions, the $\mathrm{Mg}(\mathrm{OH})_{2}$ layer may consume active materials, serve as barriers and cause capacity degradation of Mg-based alloys $[16,17]$. This detrimental phenomenon can be aggravated by the pulverization upon cycles which creates a new active surface and forms additional $\mathrm{Mg}(\mathrm{OH})_{2}$ when contacting with electrolyte [18]. In Mg-based alloys, an effective way to prohibit the capacity decay is to substitute $\mathrm{Mg}$ and/or $\mathrm{Ni}$ partially to adjust the composition. In this way, the alloy oxidation resistance can be improved in $\mathrm{KOH}$ electrolyte. Moreover, decreasing the expansion coefficient of the material following hydrogen absorption can enhance the antipulverization ability of electrodes. Adding rare earth (RE) or/and transition elements in $\mathrm{Mg}-\mathrm{Ni}$-based alloys is beneficial for enhancing electrode characteristics, especially the cycle stability which is attributed to the enhanced corrosion resistance [19-21]. Tian et al. [22] have researched the effects of Pd substituting $\mathrm{Mg}$ on the electrochemical performances of $\mathrm{Mg}_{0.9-x} \mathrm{Ti}_{0.1} \mathrm{Pd}_{x} \mathrm{Ni}(x=0.04-0.1)$ alloy. The results showed that the electrochemical cycle stability was greatly enhanced because of the newly formed passivation layer covering the alloys. By melt spinning, Zhang et al. [23] prepared $\mathrm{La}_{4} \mathrm{MgNi}_{17.5} \mathrm{Mn}_{1.5}$ alloy which composed $\mathrm{CeCu}_{5}$-type, $\mathrm{Pr}_{5} \mathrm{Co}_{19}$-type and $\mathrm{CeNi}_{2}$-type phases. They found that this alloy has better cycle stability and higher discharge capacity compared with the as-cast alloy. Yang et al. [24] improved the cycle stability and discharge kinetic performance of $\mathrm{Mg}-\mathrm{Al}-\mathrm{Ni}$ alloy by replacing partial $\mathrm{Al}$ by $\mathrm{Ti}$.

Surface modification, especially mechanical coating, is a valid way to improve Mg-based alloys' electrochemical performances. The effect of mechanical coating $\mathrm{Ni}$ or Ni-5 at $\% \mathrm{Al}$ on the $\mathrm{Mg}-50 \mathrm{wt} \% \mathrm{Ni}$ alloy has been investigated by Santos et al. [25], which exhibits a significant enhancement in cycle stability and maximal discharge capacity. Du et al. [26] introduced graphite to $\mathrm{Mg}_{2} \mathrm{Ni}$ by mechanical milling, which improved the alloy's cycle stability and increased the discharge capacity at 20th cycle from 116.9 to $178.5 \mathrm{mAh} / \mathrm{g}$. Also, Sun et al. [27] ball-milled $\mathrm{Mg}_{24} \mathrm{Ni}_{10} \mathrm{Cu}_{2}$ with Ni powder, which introduced a nanocrystalline and amorphous structure to the alloy, improved the electrochemical capacity to $899.2 \mathrm{mAh} / \mathrm{g}$ and promoted the alloy's high rate discharge capacity.

Young et al. [28] added $\mathrm{Al}$ in $\mathrm{Mg}-\mathrm{Ni}$-based alloys, which increased the cycle stability of alloys. A study made by us before showed that the discharge capacity, electrochemical kinetics and cycle stability of Mg-Ni-based alloys can be improved by adding Ce [29]. Meanwhile, a Ni coating layer, in addition to corrosion inhibition, can behave as an electrocatalytic role in electrochemical processes, like hydrogen diffusion inside alloys and charge transfer on the alloy surface. As for the present work, for obtaining a synthetic improvement on $\mathrm{Mg}-\mathrm{Ni}$-based alloy's electrochemical performances, $\mathrm{Mg}$ and $\mathrm{Ni}$ were partly substituted by $\mathrm{Ce}$ and $\mathrm{Al}$, respectively, and a Ni coating layer was made through ball milling. The influences on the electrochemical performances of $\mathrm{Mg}_{1-x} \mathrm{Ce}_{x} \mathrm{Ni}_{0.9} \mathrm{Al}_{0.1}(x=0,0.02,0.04,0.06,0.08)+50$ wt $\% \mathrm{Ni}$ composites made by milling duration and Ce content were researched. The mechanism underlying the influences was discussed. For convenience, $50 \mathrm{Ni}$ is used to symbolize $50 \mathrm{wt} \% \mathrm{Ni}$ in this study.

\section{Experimental}

The experimental alloys $\mathrm{Mg}_{1-x} \mathrm{Ce}_{x} \mathrm{Ni}_{0.9} \mathrm{Al}_{0.1}(x=0-0.08)$ were obtained through a vacuum induction furnace. The smelting environment was a $0.04 \mathrm{MPa}$ helium atmosphere for the purpose of avoiding $\mathrm{Mg}$ from volatilization. The liquid alloy was poured into a mold which was made of copper and cooled by water; thus, the cast ingots were formed. The ingots were crushed into powders with about $50 \mu \mathrm{m}$ in diameter. With a ratio of 2:1 in weight, the alloy and nickel powders were mixed. Then, a planetary-type miller was utilized to mill the mixed powders. The milling progress was under argon atmosphere for the propose of avoiding powders from being oxidized. The samples were handled in a glove box which was filled with argon to prevent oxidation. With the ratio of 35:1 in weight, grinding balls and the powders were put together in stainless steel ball mill tanks with a fixed milling speed of $135 \mathrm{rpm}$ and different milling durations of $5,10,20$ and $30 \mathrm{~h}$, respectively. For describing conveniently, Ce content is utilized to denote the alloys, just as $\mathrm{Ce}_{0}, \mathrm{Ce}_{0.02}$, $\mathrm{Ce}_{0.04}, \mathrm{Ce}_{0.06}$ and $\mathrm{Ce}_{0.08}$.

With the experimental parameters of $160 \mathrm{~mA}, 40 \mathrm{kV}$ and $10 \% \mathrm{~min}, \mathrm{X}$-ray diffraction (XRD) (D/max/2400) was utilized to determine the phase structures of sample alloys. The diffraction was performed with $\mathrm{Cu} K_{\alpha 1}$ radiation filtered by graphite. The morphologies of the as-cast $\mathrm{Mg}_{1-x} \mathrm{Ce}_{x} \mathrm{Ni}_{0.9} \mathrm{Al}_{0.1}(x=0-0.08)$ alloys were observed by using a Philips scanning electron microscope (SEM, QUANTA 400). The alloys' composition was analyzed with the help of the equipped energy-dispersive X-ray detector (EDX). The high-resolution transmission electron microscope (HRTEM, JEM-2100F) was also utilized in observation. The crystalline states were measured by electron diffraction (ED).

With the weight ratio of 1:4, the mixture of alloy and carbonyl nickel powders was cold-pressed under $35 \mathrm{MPa}$ to 
form a round electrode pellet whose diameter was $15 \mathrm{~mm}$ and weight was $1 \mathrm{~g}$. The tri-electrode open cell, containing a working electrode, a sintered $\mathrm{Ni}(\mathrm{OH})_{2} / \mathrm{NiOOH}$ counter electrode and a $\mathrm{Hg} / \mathrm{HgO}$ reference electrode, was immersed in $6 \mathrm{~mol} / \mathrm{L} \mathrm{KOH}$ electrolyte at $303 \mathrm{~K}$ and used to measure the samples' electrochemical performances. The potential difference between the reference and negative electrodes is discharge voltage. In the process of testing the electrochemical property of an alloy electrode, the electrode was fully charged with a constant current density of $60 \mathrm{~mA} / \mathrm{g}$ at first. Then, after a 15-min rest, the alloy electrode was discharged with different current densities till $-500 \mathrm{mV}$ for measuring different electrochemical properties. The discharge current remained $60 \mathrm{~mA} / \mathrm{g}$ when measuring the activation capability and discharge potential curve. The discharge current density for testing alloys' capacity retaining rate was set at $300 \mathrm{~mA} / \mathrm{g}$. For getting alloys' high rate discharge ability, the electrode was discharging at different current densities of $300,600,900$ and $1200 \mathrm{~mA} / \mathrm{g}$, respectively.

The measurements of electrochemical impedance spectra (EIS) and potentiodynamic polarization curves at $303 \mathrm{~K}$ of samples were taken with the electrochemical workstation of PARSTAT 2273. Before measurement, a series of electrochemically charge and discharge cycling were performed for the propose of activating experimental materials. When the fresh electrodes were charged fully, it needed to rest for
$2 \mathrm{~h}$ for making the open circuit potential stable. The EIS of alloys were measured after discharging for $50 \%$ depth. The frequency range was from $10 \mathrm{kHz}$ to $5 \mathrm{MHz}$, the alternating current amplitude was $5 \mathrm{mV}$, and the point number of each curve was 60 . With the potential ranging from -1.2 to $+1.0 \mathrm{~V}$ and scan rate being $5 \mathrm{mV} / \mathrm{s}$, the potentiodynamic polarization curves were measured. As for potentiostatic discharge, the fully charged electrodes were discharging at $500 \mathrm{mV}$ for $5000 \mathrm{~s}$ at the electrochemical workstation.

\section{Results and Discussion}

\subsection{Microstructure Characterization}

Figure 1 presents the XRD images of as-milled $\mathrm{Mg}_{1-x} \mathrm{Ce}_{x} \mathrm{Ni}_{0.9} \mathrm{Al}_{0.1}(x=0-0.08)+50 \mathrm{Ni}$ composites. Just as what we can see from it, the diffraction peaks of as-milled $(30 \mathrm{~h})$ alloys are broad and flat, revealing there exists an amorphous and nanocrystalline structure. When extending milling duration from 5 to $30 \mathrm{~h}$, the diffraction peaks are considerably broadened, indicating the appearance of amorphization or/and nanocrystallization. Generally, inhomogeneous strain and grain size change can be used to explain the broadening of diffraction peaks. With the prolongation of
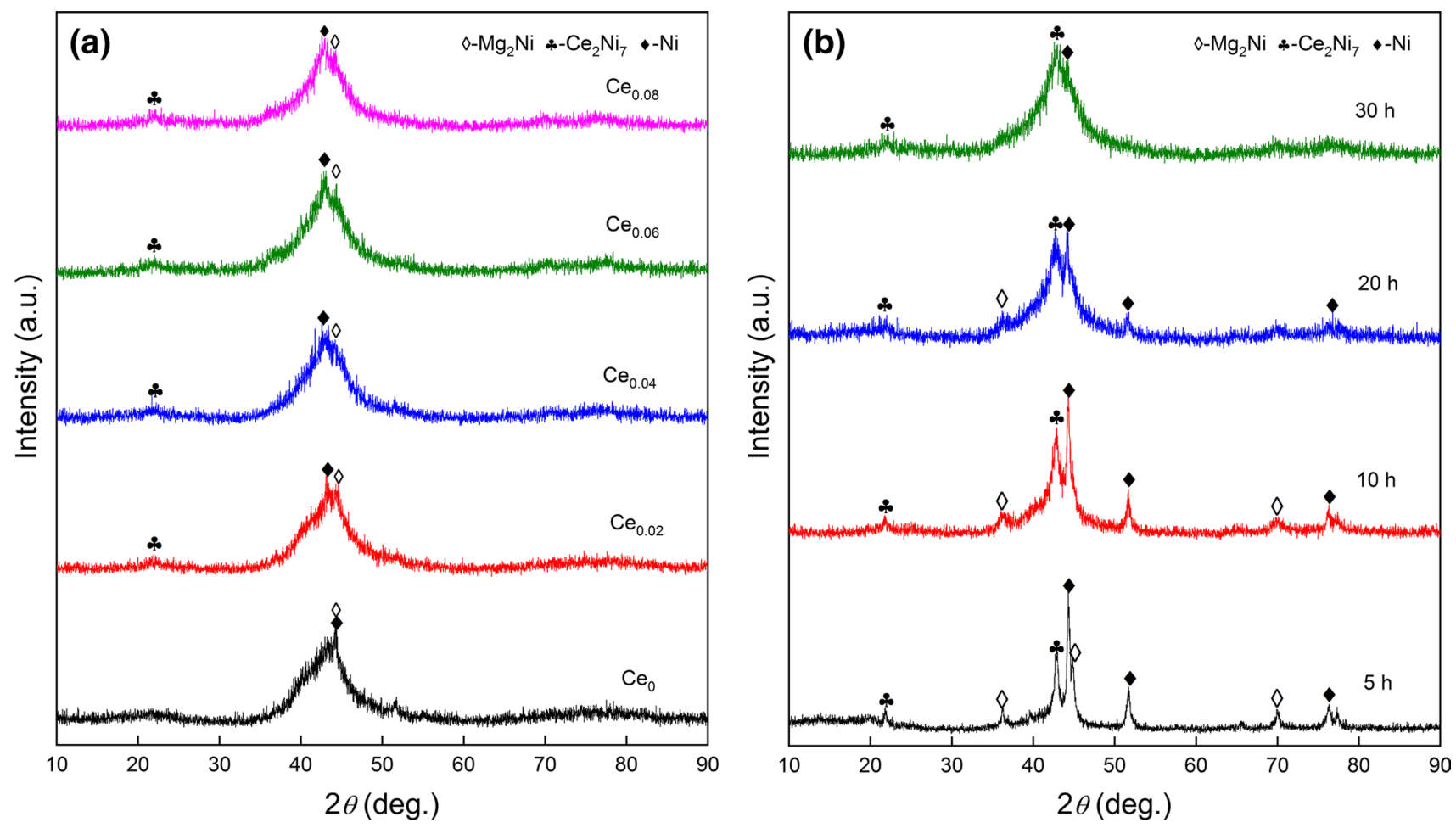

Fig. 1 XRD profiles of sample alloys: a as-milled $\mathrm{Mg}_{1-x} \mathrm{Ce}_{x} \mathrm{Ni}_{0.9} \mathrm{Al}_{0.1}(x=0-0.08)+50 \mathrm{Ni}$ alloys milled for $30 \mathrm{~h}$, b Ce $\mathrm{e}_{0.08}$ alloy for different milled time 
milling time, the diffraction peaks become broader, meaning the elevation of internal stress and defects inside materials.

SEM and the equipped EDX were used to measure the as-cast alloys. The SEM images and EDX curves are shown in Fig. 2. A dramatic refinement happens in the grains of ascast alloys with Ce substitution for $\mathrm{Mg}$. Similar results have been found in the investigations of $\mathrm{A}_{2} \mathrm{~B}_{7}$-type and $\mathrm{AB}_{2}$-type alloys $[29,30]$. The grain refinement is in favor of enhancing the strength and toughness of alloys, consequently improving their anti-pulverization capability [31]. Synthetically analyzing the XRD curves above and the EDX curves as shown in Fig. 2e-g, the composition of different phases can be confirmed. Some similar results have been reported by other researchers [32-34].

As seen in Fig. 3, HRTEM was used to analyze the morphological characteristic and crystal state of the as-milled $\mathrm{Mg}_{1-x} \mathrm{Ce}_{x} \mathrm{Ni}_{0.9} \mathrm{Al}_{0.1}(x=0-0.08)+50 \mathrm{wt} \% \mathrm{Ni}$ composites. Through observing Debye-Scherrer rings, an amorphous and nanocrystalline structure can be confirmed. The proportion of amorphous phase increases with Ce content and milling time grow. Obviously, with milling duration extending from 10 to $30 \mathrm{~h}$, the disordered degree elevates and the grain sizes conspicuously shrink. Mechanical milling leads to an amorphous structure and ultrafine grains because it causes non-stabilization of the lattice and stores large quantity of internal energy. Furthermore, in the as-milled alloys, lots of different crystal defects appear, like dislocations, crystal boundaries and stacking faults. As crystal defects provide low activation energy sites, hydrogen diffusion will be accelerated when many lattice defects exist [35].

\subsection{Electrochemical Performances}

In Fig. 4, the effects of cycling number on the discharge capacity of as-milled specimens at $60 \mathrm{~mA} / \mathrm{g}$ are delineated. Clearly, at the first discharging process, the as-milled alloy can reach its maximum discharge capacity with no activation, meaning the experimental alloys possess a remarkable activation property. The Ce substitution for $\mathrm{Mg}$ does not weaken the activation capability of alloys. It is necessary for the materials in Ni-MH batteries to be activated easily. Apparently, the experimental alloys show better activation capability than the alloys that need several charging and discharging cycles before attaining maximum discharge capacity, such as $\mathrm{AB}_{5}$-type alloys. The outstanding activation performances are considered to be related to the coating $\mathrm{Ni}$ which results in the formation of an active surface. Besides, it is a crucial part to elevate the activation capability that ball milling is able to produce a lot of interfaces by creating ultrafine grains and nanocrystalline. Ma et al. [36] reported
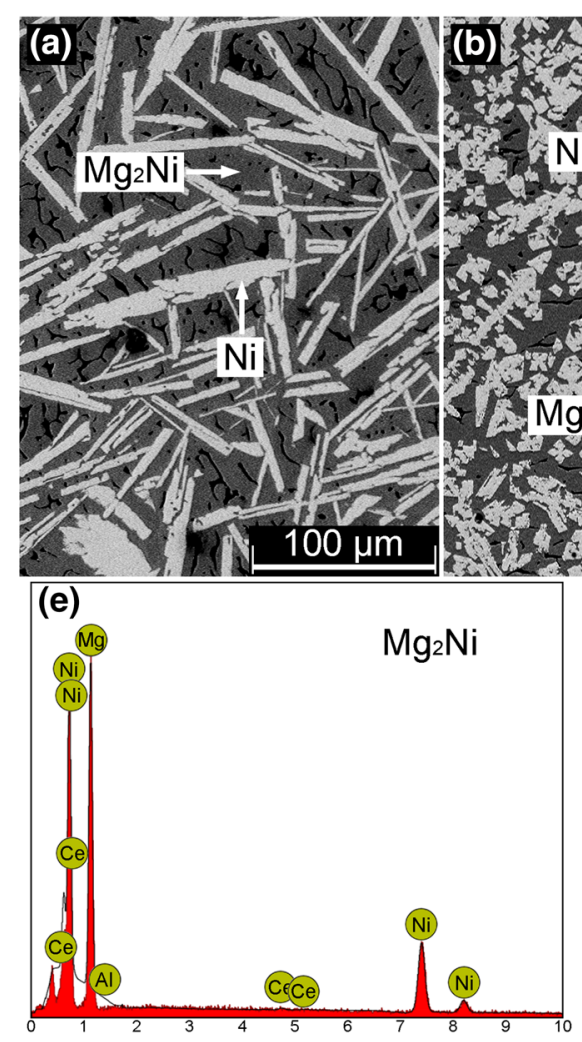

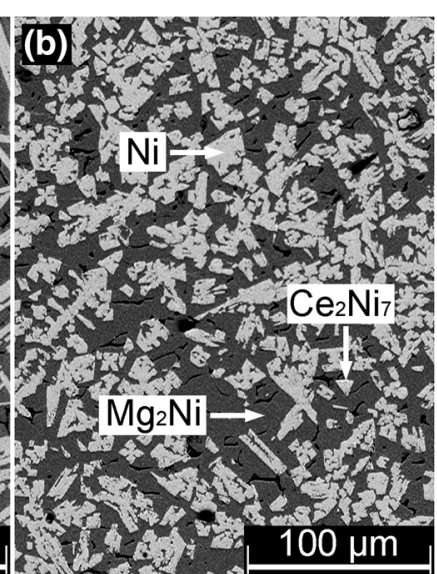

(f)

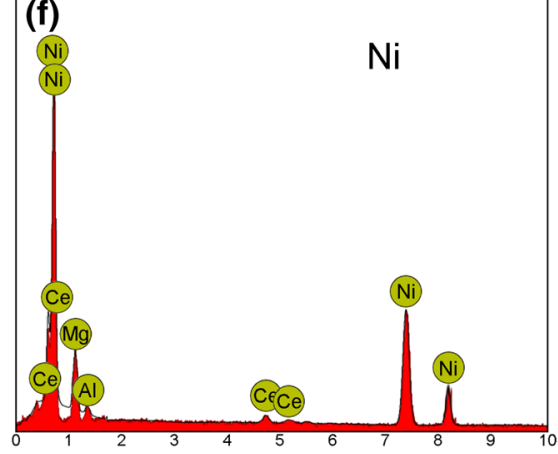

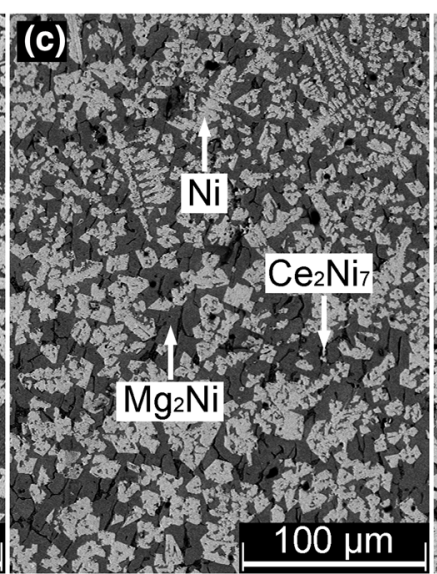

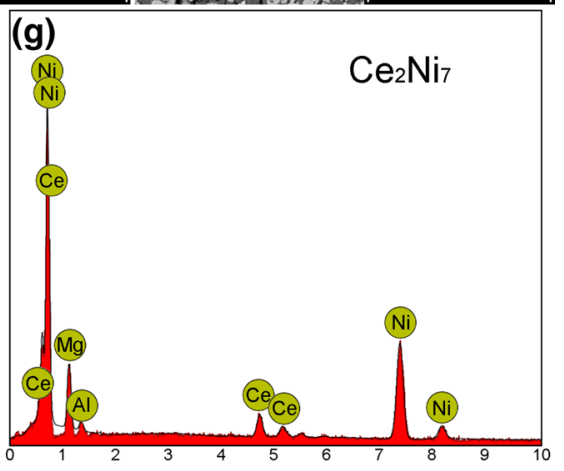

Fig. 2 SEM images and EDX curves of the as-cast $\mathrm{Mg}_{1-x} \mathrm{Ce}_{x} \mathrm{Ni}_{0.9} \mathrm{Al}_{0.1}(x=0-0.08)$ alloys: a-d SEM of $\mathrm{Ce}_{0}, \mathrm{Ce}_{0.04}, \mathrm{Ce}_{0.06}$ and Ce $\mathrm{Ce}_{0.08}$ alloys, e-g EDX of $\mathrm{Mg}_{2} \mathrm{Ni}$, $\mathrm{Ni}$ and $\mathrm{Ce}_{2} \mathrm{Ni}_{7}$ 

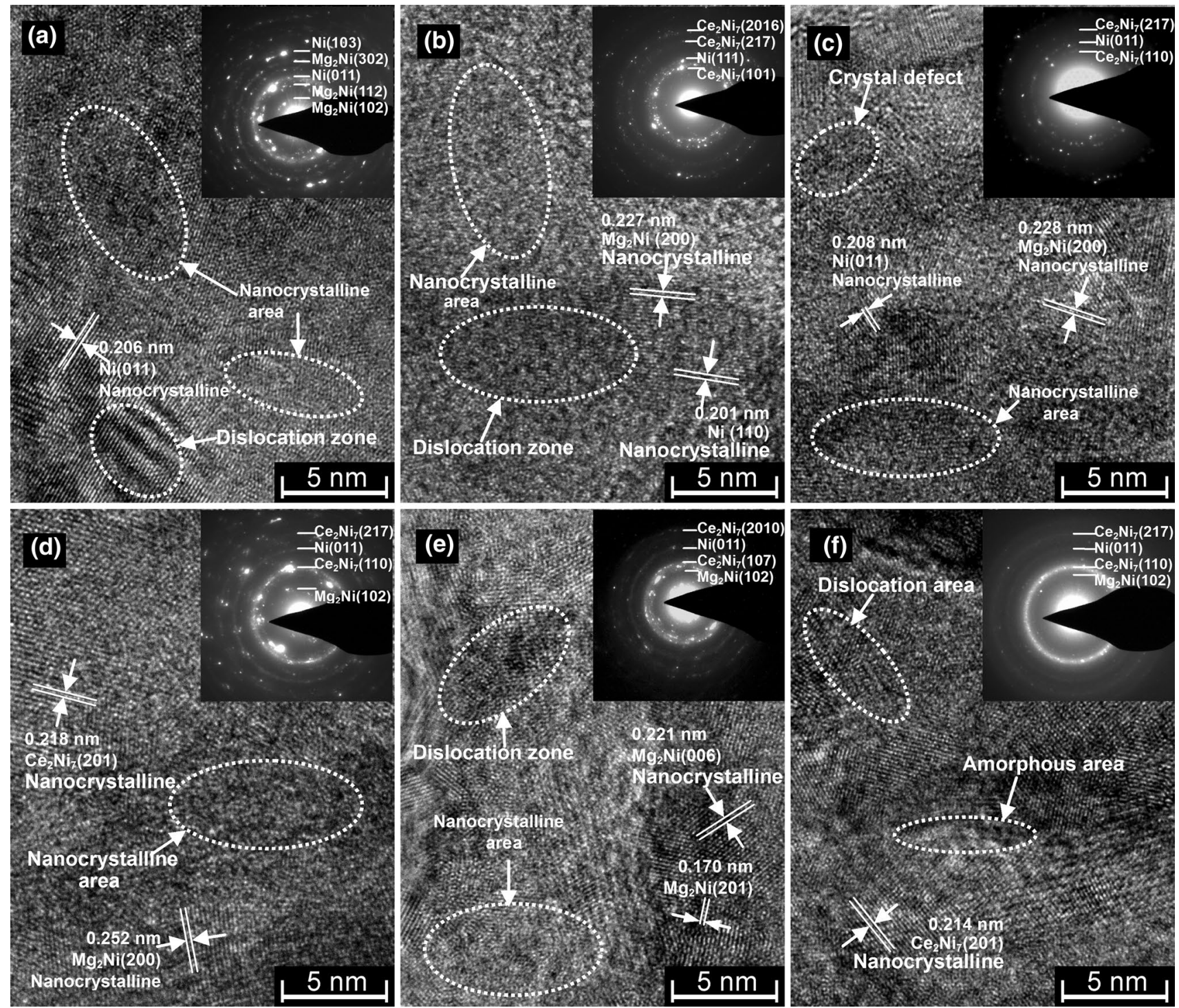

Fig. 3 HRTEM micrographs and ED patterns of the as-milled $\mathrm{Mg}_{1-x} \mathrm{Ce}_{x} \mathrm{Ni}_{0.9} \mathrm{Al}_{0.1}(x=0-0.08)+50 \mathrm{Ni}$ alloys milled for different durations: a-c $\mathrm{Ce}_{0}, \mathrm{Ce}_{0.04}$ and $\mathrm{Ce}_{0.06}$ alloys milled for $10 \mathrm{~h} ; \mathbf{d}-\mathbf{f} \mathrm{Ce}_{0.08}$ alloy milled for $10 \mathrm{~h}, 20 \mathrm{~h}$ and $30 \mathrm{~h}$

that compared with polycrystalline nickel, nanocrystalline nickel can stick hydrogen on the electrode surface much stronger. Thus, it can elevate the activation property of the electrodes and accelerate the dissociation reaction of hydrogen. Chen et al. [37] ball-milled $\mathrm{Mg}_{2} \mathrm{NiH}_{4}$ with nano-nickel, which is beneficial for promoting the charge transfer reaction on alloy surface and the hydrogen diffusion inside hydride bulk, thus, leading to an enhancement of the activation performance of the sample electrode. Li et al. [38] drew a similar conclusion as well.

Capacity retaining rate $\left(S_{n}\right)$ can be utilized to characterize the ability of restraining capacity degradation of an alloy electrode which is known as cycle stability and calculated by $S_{n}=C_{n} / C_{\max } \times 100 \%$. The maximal discharge capacity is represented by $C_{\max }$ and the discharge capacity of the $n$th dis- $/$ charging cycle is symbolized by $C_{n}$ in the previous equation. In this experiment, the discharge current density was set at $300 \mathrm{~mA} / \mathrm{g}$ for testing alloys' capacity retaining rate. For the 30-h-milled alloys, the $C_{\max }$ values are 412.6, 463.8, $519.4,469.8$ and $450.8 \mathrm{mAh} / \mathrm{g}$, respectively, with Ce content increases from $x=0$ to $x=0.08$. As for the $\mathrm{Ce}_{0.08}$ alloy, when milling time increases from 5 to $30 \mathrm{~h}$, the $C_{\max }$ values are $197.4,321.8,422.5$ and $450.8 \mathrm{mAh} / \mathrm{g}$, respectively. Figure 5 shows the evolution of $S_{n}$ value of sample alloys when the cycle number is an independent variable, which clearly reflects the decay process of discharge capacity. When $\mathrm{Ce}$ content and milling duration increase, the degradation rate of discharge capacity diminishes drastically. For directly showing the effect of Ce content and milling duration on cycle stability, we take the capacity retaining rate of the 100th 

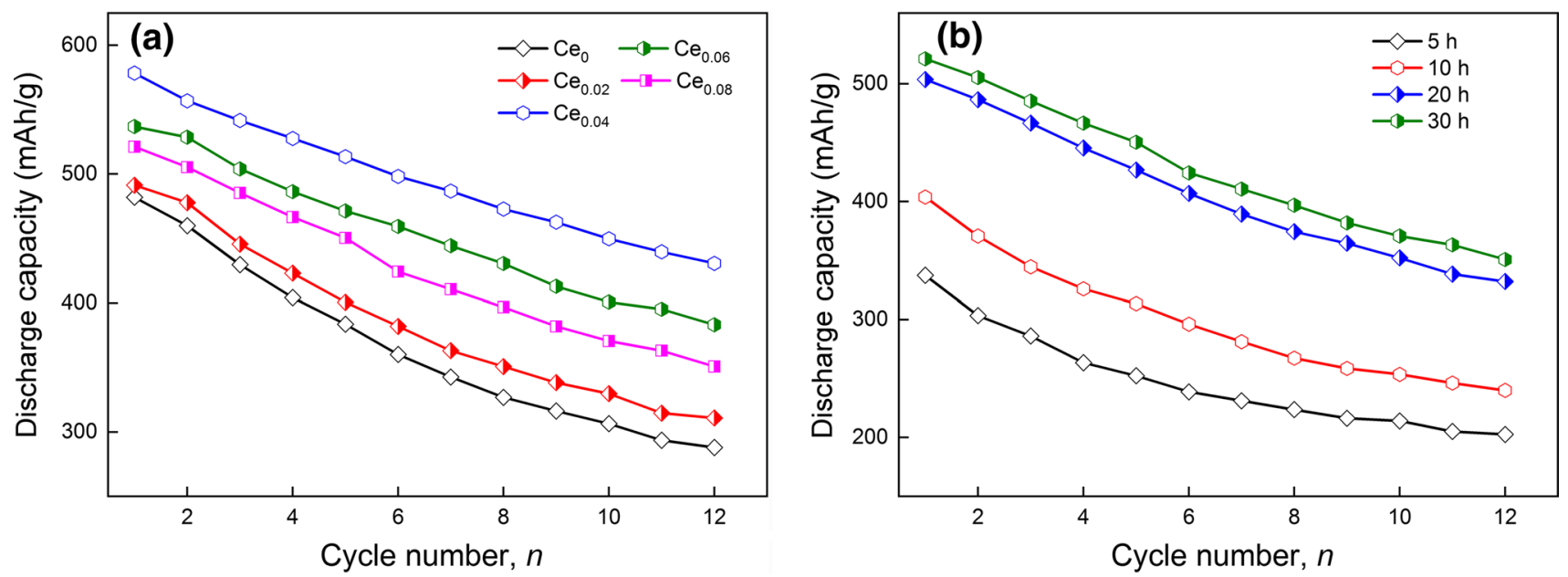

Fig. 4 Evolution of the discharge capacity of sample alloys: (a) as-milled $\mathrm{Mg}_{1-x} \mathrm{Ce}_{x} \mathrm{Ni}_{0.9} \mathrm{Al}_{0.1}(x=0-0.08)+50 \mathrm{Ni}$ alloys milled for $30 \mathrm{~h}$, (b) $\mathrm{Ce}_{0.08}$ alloy for different milled times
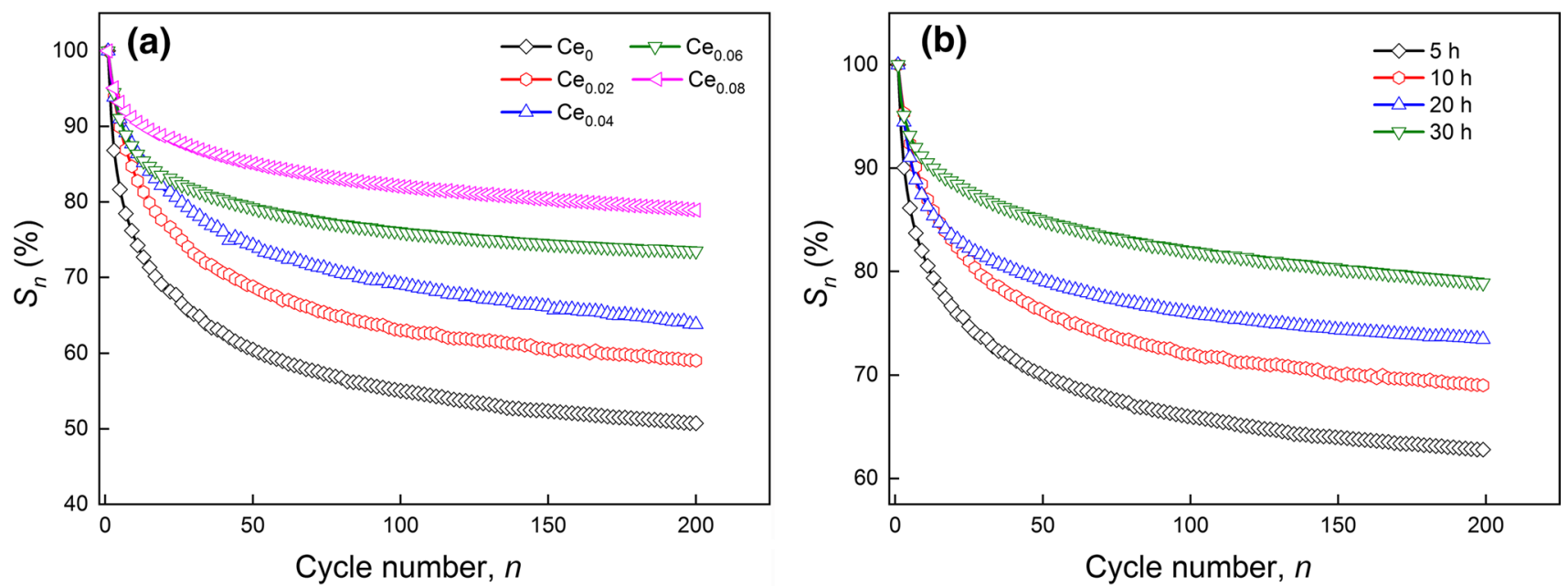

Fig. 5 Evolution of the capacity retaining rates $\left(S_{n}\right)$ of sample alloys: a as-milled $\mathrm{Mg}_{1-x} \mathrm{Ce}_{x} \mathrm{Ni}_{0.9} \mathrm{Al}_{0.1}(x=0-0.08)+50 \mathrm{Ni}$ alloys milled for $30 \mathrm{~h}$, b $\mathrm{Ce}_{0.08}$ alloy for different milled time

cycle $\left(S_{100}\right)$ as a criterion. Hence, the $S_{100}$ value dependence of Ce content and milling duration can be obtained and is provided in Fig. 6. The $S_{100}$ value markedly grows when Ce content and milling duration increase. To be specific, the $S_{100}$ value of 30 -h-milled alloys rises from 55 to $82 \%$ with Ce content increasing from 0 to 0.08 and it augments from 66 to $82 \%$ for $\mathrm{Ce}_{0.08}$ alloy when milling duration extending from 5 to $30 \mathrm{~h}$.

For investigating how ball milling and Ce substitution affect the cycle stability of alloys positively, the SEM images of alloys before and after electrochemical cycles and the XRD curve of $\mathrm{Ce}_{0.08}$ after cycling were measured, as shown in Fig. 7. After several electrochemical cycles, some cracks appear on the alloy particle surface. Comparing Fig. 7b and $\mathrm{c}$, we find that the cracks decrease with milling time prolonging, which means the increase in alloy's cycle stability. This cycle stability enhancement is thought to be in connection with the formation of a dense Ni coating layer. During mechanical milling progress, through the repeated collision between balls and powders, nickel will be deformed mechanically and form a coating layer covering alloy particles because of the ductility of Ni. Apparently, the compactness of $\mathrm{Ni}$ coating layer increases when prolonging milling duration, which enhances the alloy's corrosion resistance and cycle stability. The XRD curve of 30-h-milled $\mathrm{Ce}_{0.08}$ alloy reveals that $\mathrm{Ce}$ in $\mathrm{Mg}$-based alloys will transform into $\mathrm{CeO}_{2}$ after charging/discharging cycles in $6 \mathrm{~mol} / \mathrm{L} \mathrm{KOH}$ electrolyte. $\mathrm{CeO}_{2}$ is insoluble and compact in alkaline aqueous solution. When the $\mathrm{CeO}_{2}$ grains intersperse in the poriferous $\mathrm{Mg}(\mathrm{OH})_{2}$ layer, a corrosion-resistant passive film 

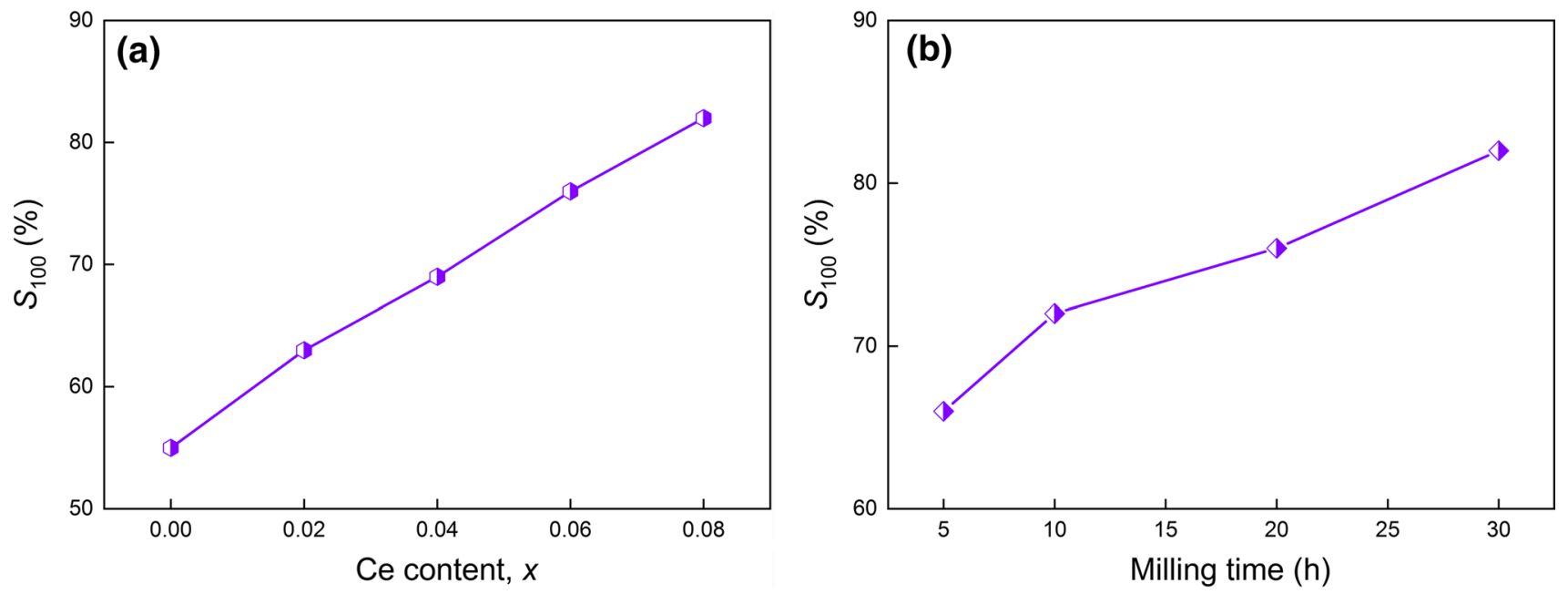

Fig. 6 Evolution of the capacity retaining rates $\left(S_{n}\right)$ of sample alloys: a as-milled $\mathrm{Mg}_{1-x} \mathrm{Ce}_{x} \mathrm{Ni}_{0.9} \mathrm{Al}_{0.1}(x=0-0.08)+50 \mathrm{Ni}$ alloys milled for $30 \mathrm{~h}$, b $\mathrm{Ce}_{0.08}$ alloy for different milled times
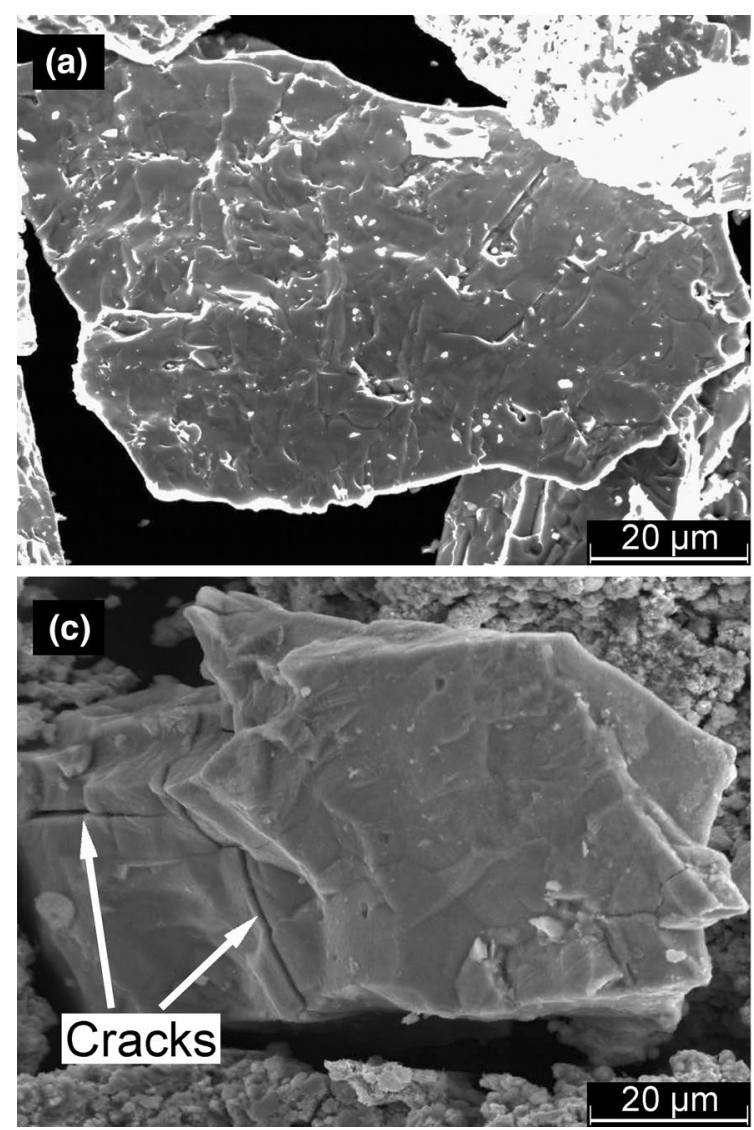
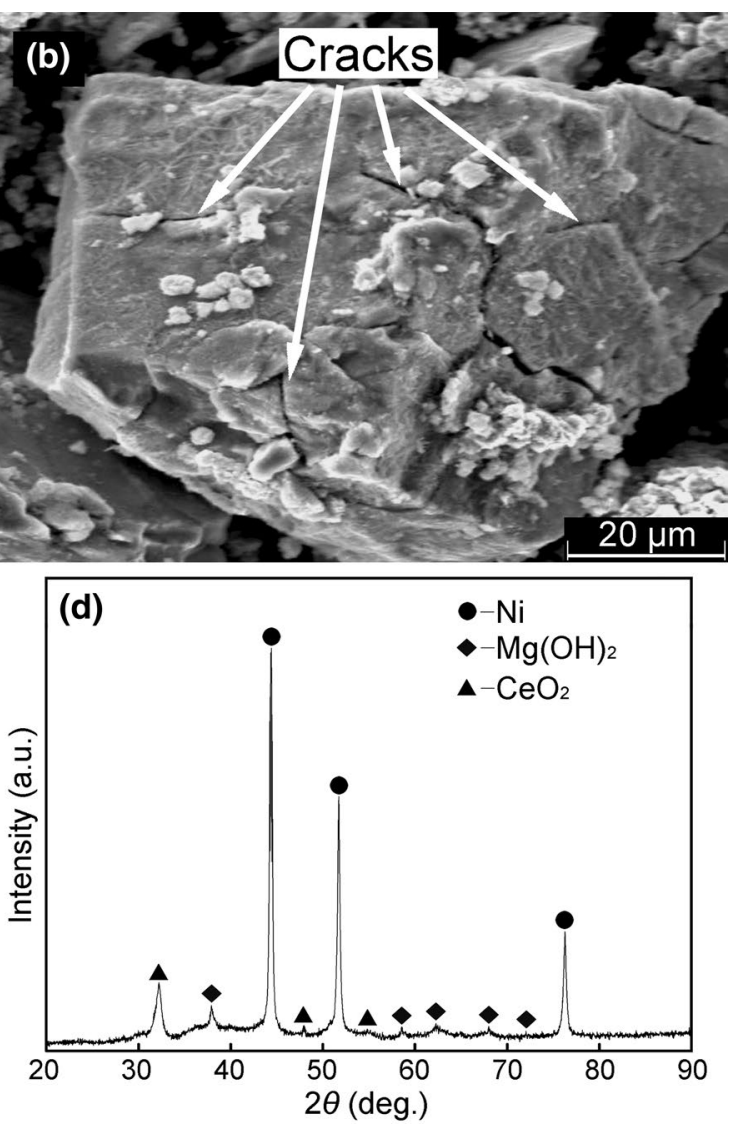

Fig. 7 SEM images before and after electrochemical cycles and XRD curve after cycling of $\mathrm{Ce}_{0.08}$ alloy: a 5-h-milled Ce $\mathrm{e}_{0.08}$ before cycling, $\mathbf{b}$ 5-h-milled $\mathrm{Ce}_{0.08}$ after cycling, c 30-h-milled $\mathrm{Ce}_{0.08}$ after cycling, $\mathbf{d}$ 30-h-milled $\mathrm{Ce}_{0.08}$ after cycling

will form. The passive film makes the $\mathrm{OH}^{-}$ion penetration difficult and prevents the inner alloy from oxidization, which results in the improvement corrosion resistance and cycle stability of alloys. The advantage of core-shell structure has been reported by many researchers as well. Sun et al. [39] coated $\mathrm{Ti}_{1.4} \mathrm{~V}$ alloy with a $\mathrm{Cu}$ layer. The coating layer can enhance not only the electrochemical hydrogen storage capacity, but also the corrosion resistance. Lu et al. [40] 
covered the metal-nitride supercapacitor electrodes with a thin carbon shell. The carbon shell can improve the cycle stability of electrodes by suppressing their electrochemical oxidation reactions. Transition metals and rare earth elements were also used to prepare core-shell structured $\mathrm{Mg}$ based composites [41-43]. The transition metal or rare earth oxide shells showed good catalysis, especially in dehydrogenation progress.

Figure 8 shows the discharge potential curves of specimens. The potential plateau in discharge curves can characterize a battery of its discharge potential characteristics and the stability of output power. The output power will be more stable when the discharge plateau turns more horizontal and longer. Notably, just like the experimental alloys shown in Fig. 8, slope potential plateaus exist in all discharge potential curves of Mg-based alloys as a common feature, which has been reported by many kinds of references [44-46]. Increasing Ce content and milling duration will conspicuously increase the discharge potential and prolong the discharge plateau, thus improving the discharge potential characteristics of electrodes. The potential characteristics of batteries are compactly related to their internal resistance which includes ohmic internal resistance and polarization resistance. The internal resistance will decrease with the hydrogen diffusing coefficient increasing [47]. Lots of efficient diffusion paths for hydrogen atoms are provided by grain boundaries. Increasing $\mathrm{Ce}$ content and milling duration will improve the refinement of alloy grains, which will provide more grain boundaries, thus improving the potential characteristics [48]. In Fig. 8, the discharge capacities as a function of Ce content and milling duration are depicted. The discharge capacity initially ascends and subsequently descends for the 30-h-milled alloys when increasing Ce content, while it always grows with milling duration prolonging for the $\mathrm{Ce}_{0.08}$ alloy. Concretely, the discharge capacity augments firstly from $482 \mathrm{mAh} / \mathrm{g}\left(\mathrm{Ce}_{0}\right)$ to $578.4 \mathrm{mAh} / \mathrm{g}$ $\left(\mathrm{Ce}_{0.04}\right)$, soon after decreases to $521.2 \mathrm{mAh} / \mathrm{g}\left(\mathrm{Ce}_{0.08}\right)$ for the 30-h-milled alloys, but that of $\mathrm{Ce}_{0.08}$ alloy grows from 337.4 to $521.2 \mathrm{mAh} / \mathrm{g}$ with the prolongation of milling time from 5 to $30 \mathrm{~h}$. Many researchers have reported the advantageous effects caused by Ce substituting $\mathrm{Mg}$ on the discharge capacity of Mg-based alloys. Spassov et al. [49] reported that adding rare earth element into $\mathrm{Mg}-\mathrm{Ni}$-based alloys can improve their glass formation and hydrogen absorption. $\mathrm{Ma}$ et al. [50] introduced $\mathrm{Ce}$ in a $\mathrm{Mg}-\mathrm{Li}-\mathrm{Al}-\mathrm{Ce}$ alloy, which increased its anti-corrosion ability and electrochemical activity. Yartys et al. [51] obtained the best electrochemical property of RE-Mg-Ni-based alloys by adjusting the proportion of rare earth element. As for the positive side of prolonging milling duration acting on discharge capacity is related to the refined grains since the maximal hydrogen concentration distributes at grain boundaries [52]. Besides, in the charge/discharge process, the electrodes performances will be enhanced by the homogeneously dispersed $\mathrm{Ni}$ inclusions which can provide electrocatalytic sites and impair the charge transfer resistance.

\subsection{Electrochemical Kinetics}

It is a common method to analyze the electrochemical kinetics of alloy electrodes through high rate discharge ability (HRD). The HRD value can be gotten through the formula of $\mathrm{HRD}=C_{i} / C_{60} \times 100 \%$. In this formula, the maximal discharge capacity of an electrode during charging/discharging processes at $i \mathrm{~mA} / \mathrm{g}$ is represented by $C_{i}$ and the maximal discharge capacity at $60 \mathrm{~mA} / \mathrm{g}$ is represented by $C_{60}$. Figure 9 presents the variety of the HRDs with discharge current density. The HRD distinctly declines when current
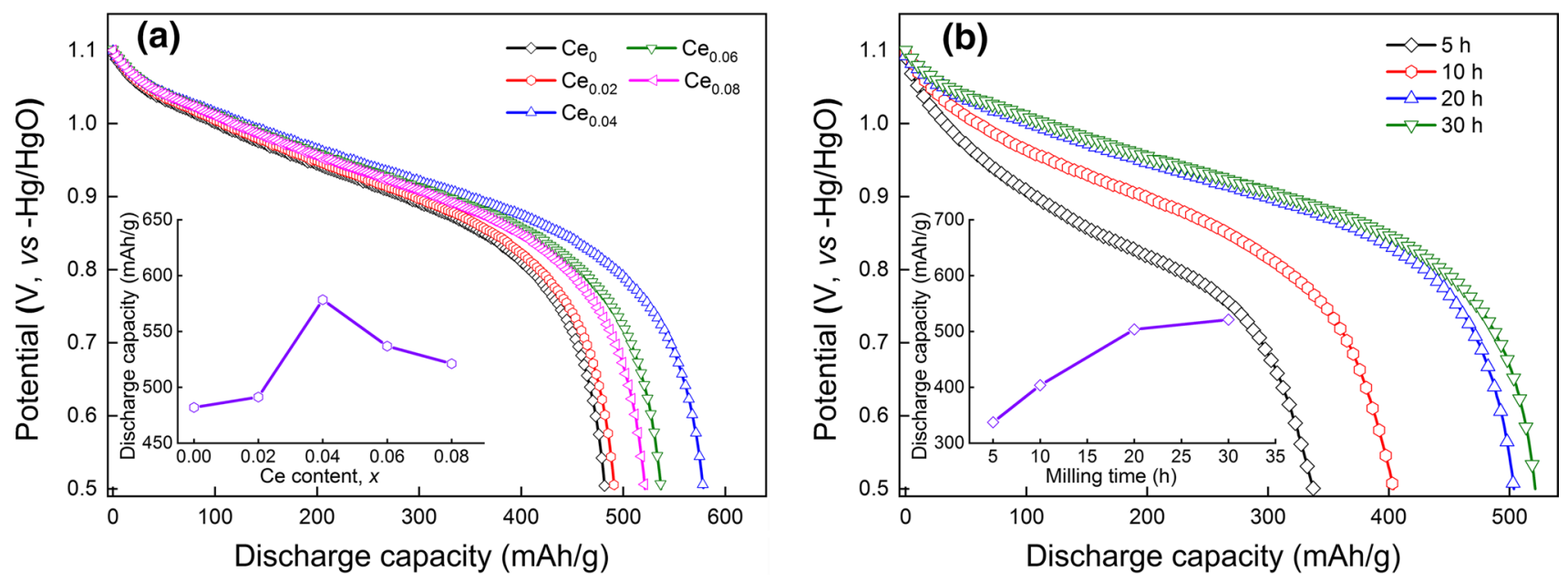

Fig. 8 Discharge potential curves of sample alloys: a as-milled $\mathrm{Mg}_{1-x} \mathrm{Ce}_{x} \mathrm{Ni}_{0.9} \mathrm{Al}_{0.1}(x=0-0.08)+50 \mathrm{Ni}$ alloys milled for $30 \mathrm{~h}$, b Ce 0.08 alloy for different milled times 

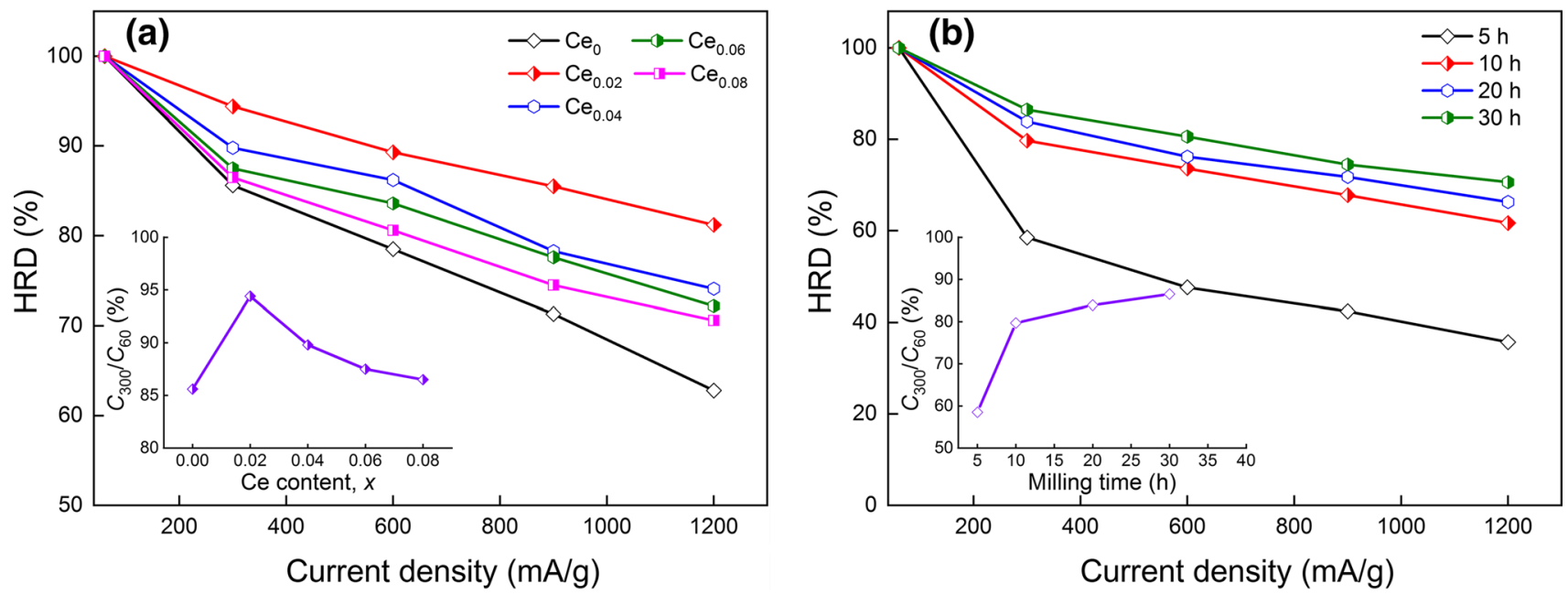

Fig. 9 Evolution of the HRD of sample alloys: a as-milled $\mathrm{Mg}_{1-x} \mathrm{Ce}_{x} \mathrm{Ni}_{0.9} \mathrm{Al}_{0.1}(x=0-0.08)+50 \mathrm{Ni}$ alloys milled for $30 \mathrm{~h}$, b Ce $\mathrm{e}_{0.08}$ alloy for different milled times

density rises. For directly showing the effect of Ce content and milling duration on HRD values, the current density of $300 \mathrm{~mA} / \mathrm{g}$ was set as a criterion. The insets in Fig. 9 represent the HRD dependence on Ce content and milling duration. In this experiment, the HRD value initially mounts up then subsequently cuts down when Ce content rises, while it always grows up with milling duration prolonging. Concretely, the HRD $\left(\mathrm{HRD}=C_{300} / C_{60}\right)$ firstly increases from $85.6 \%\left(\mathrm{Ce}_{0}\right)$ to $94.4 \%\left(\mathrm{Ce}_{0.02}\right)$, soon after goes down to $86.5 \%\left(\mathrm{Ce}_{0.08}\right)$ for 30-h-milled alloys, but it augments from 58.5 to $86.5 \%$ for the $\mathrm{Ce}_{0.08}$ alloy while prolonging milling time from 5 to $30 \mathrm{~h}$.

Generally speaking, electrochemical hydrogen storage kinetics principally depends on two things, viz. charge transferring on electrode surface and hydrogen diffusing inside electrode [53]. For the purpose of deeply understanding the kinetic mechanism, studying how Ce content and milling duration work on the hydrogen diffusing and charge transferring is very necessary. It is suggested by Volodin et al. [54] that the hydrogen diffusion coefficient $(D)$ can be analyzed through potential-step method. Figure 10 shows the semilogarithmic curves of discharging current density versus discharging time of the fully charged samples. It is observed that the lgi value drops sharply at the beginning, which is related to the electro-oxidation as it reduces the hydrogen concentration absorbed on the electrode surface. Soon afterward, the main decisive factor transfers from the electro-oxidation to hydrogen diffusion, so these curves
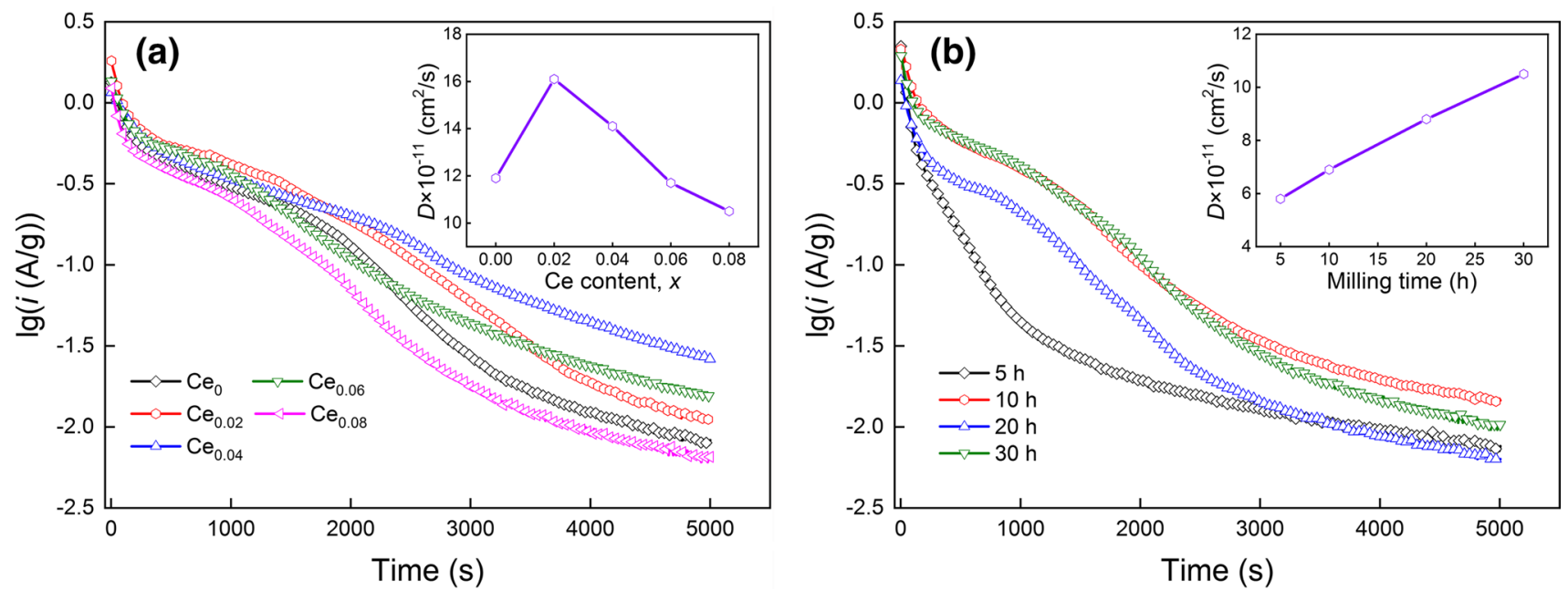

Fig. 10 Semilogarithmic curves of anodic current vs. time responses of sample alloys: a as-milled $\mathrm{Mg}_{1-x} \mathrm{Ce}_{x} \mathrm{Ni}_{0.9} \mathrm{Al}_{0.1}(x=0-0.08)+50 \mathrm{Ni}$ alloys milled for $30 \mathrm{~h}, \mathbf{b} \mathrm{Ce}_{0.08}$ alloy for different milled times 
become linear. The $D$ value of electrodes can be estimated by the following equation with the fitting lines of the linear part of the curves demonstrated in Fig. 10 [55]:

$$
\begin{aligned}
& \lg i=\lg \left[ \pm 6 F D\left(C_{0}-C_{\mathrm{s}}\right) /\left(d a^{2}\right)\right]-\pi^{2} D t /\left(2.303 a^{2}\right), \\
& D=-2.303 a^{2}[\mathrm{~d}(\lg i) / \mathrm{d}(\lg t)] / \pi^{2} .
\end{aligned}
$$

In these equations, the diffusion current density is represented by $i(\mathrm{~A} / \mathrm{g})$, hydrogen diffusion coefficient is represented by $D\left(\mathrm{~cm}^{2} / \mathrm{s}\right)$, the initial hydrogen concentration inside alloy and hydrogen concentration on the alloy surface are symbolized by $C_{0}$ and $C_{\mathrm{s}}\left(\mathrm{mol} / \mathrm{cm}^{3}\right)$, respectively, $a$ means the alloy particle radius $(\mathrm{cm}), d$ stands for the alloy density $\left(\mathrm{g} / \mathrm{cm}^{3}\right)$, and $t$ represents discharging time (s). The dependences of $D$ value on Ce content and milling time are insets in Fig. 10. Evidently, $D$ has a maximal value with $\mathrm{Ce}$ content varying, while it keeps growing up when prolonging milling time.

Limit current density $\left(I_{\mathrm{L}}\right)$ is another crucial kinetic parameter connected with hydrogen diffusing rate. Potentiodynamic polarization curves were measured to get the $I_{\mathrm{L}}$ value, as presented in Fig. 11. The $I_{\mathrm{L}}$ value is the value of the current density at the inflection point in each potentiodynamic polarization curve. Usually, the $I_{\mathrm{L}}$ is treated as the critical current density for passivation as oxidizing reactions take place at $I_{\mathrm{L}}$ and result in an oxidation layer covering the electrodes which will prevent hydrogen atoms from further penetrating [56]. With the data of Fig. 11, the influences of Ce content and milling duration on $I_{\mathrm{L}}$ value can be built, as the insets in Fig. 11 show. Evidently, $I_{\mathrm{L}}$ grows up firstly then decreases when rising Ce content, while it always increases when prolonging milling duration.

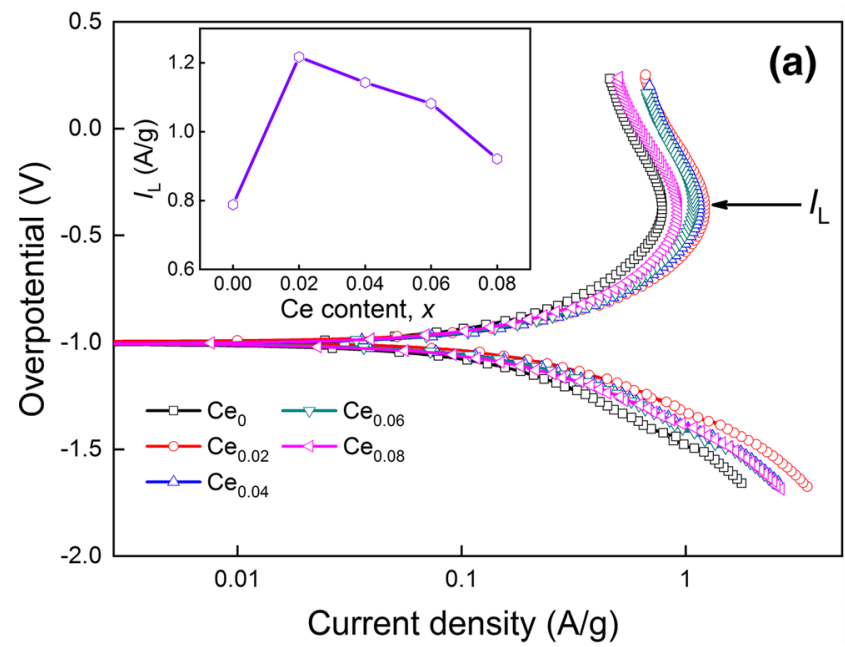

Electrochemical impedance spectrum (EIS) was measured for assessing the charge transfer rate on the electrode surface based on Kuriyama's model [57]. The EIS curves of the as-milled $\mathrm{Ce}_{0.08}$ alloy, as a typical representative, are demonstrated in Fig. 12. The EIS curves show two circular arcs in the high and middle-frequency regions and show a line in the low-frequency region. The smaller semicircle in the high-frequency region symbolizes the contact resistance between alloy powders and conductive material. The charge transfer resistance $\left(R_{\mathrm{ct}}\right)$ on alloy surface is reflected by the larger semicircle in the middle-frequency region. The linear part corresponding to the low-frequency region represents Warburg impendence. Relying on the equivalent circuit as shown in Fig. 12, we can use the fitting program Z-View to get the fitting line and the $R_{\mathrm{ct}}$ value easily. $R_{\mathrm{ct}}$ is mainly

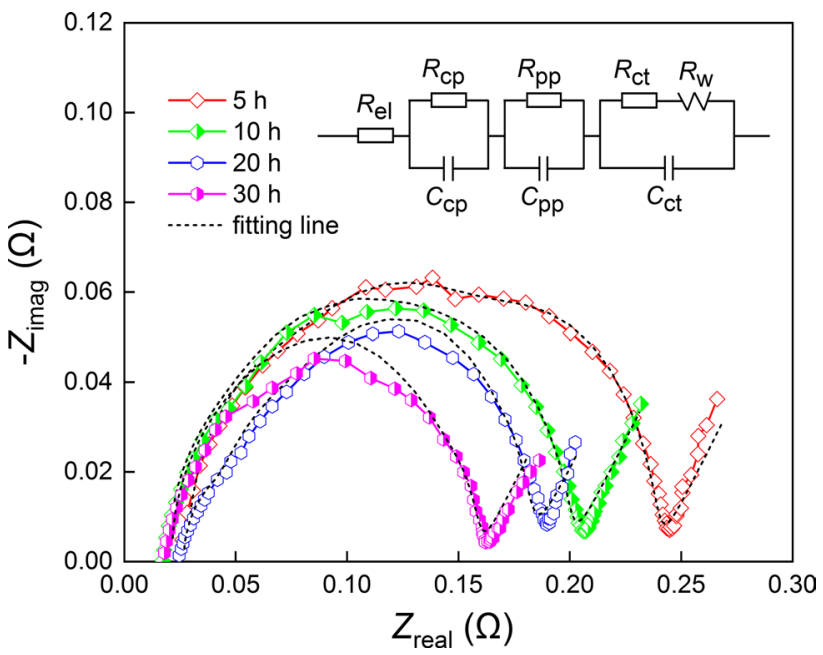

Fig. 12 Electrochemical impedance spectra (EIS) of the $\mathrm{Ce}_{0.08}$ alloy milled for different times and the equivalent circuit

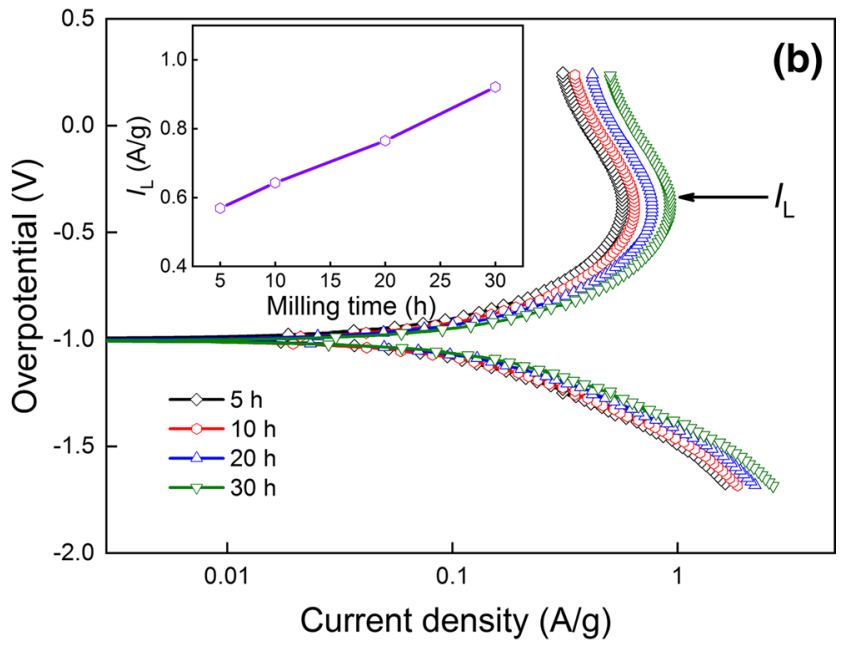

Fig. 11 Potentiodynamic polarization curves of sample alloys: a as-milled $\mathrm{Mg}_{1-x} \mathrm{Ce}_{x} \mathrm{Ni}_{0.9} \mathrm{Al}_{0.1}(x=0-0.08)+50 \mathrm{Ni}$ alloys milled for $30 \mathrm{~h}$, b $\mathrm{Ce}_{0.08}$ alloy for different milled times 
related to the electrochemical reactivity of the alloy surface as Kuriyama et al. [57] considered. The electrochemical reactivity of alloy surface basically depends on the apparent activation enthalpy change $\left(\Delta_{\mathrm{r}} H^{*}\right)$ which is available by using the equation followed [58]:

$\ln \left[\left(T / R_{\mathrm{ct}}\right) /(\mathrm{K} / \Omega)\right]=C_{0}-\Delta_{\mathrm{r}} H^{*} /(R T)$.

In this equation, the charge transfer resistance is represented by $R_{\mathrm{ct}}$, the temperature of samples is represented by $T, K$ and $\Omega$ are the units of temperature and resistance, respectively, $R$ is the gas constant, and $C_{0}$ stands for a constant in which the surface area is considered. The EIS curves of $\mathrm{Mg}_{1-x} \mathrm{Ce}_{x} \mathrm{Ni}_{0.9} \mathrm{Al}_{0.1}(x=0-0.08)+50 \mathrm{Ni}$ alloys at 303,318 and $333 \mathrm{~K}$ were measured for getting the $\Delta_{\mathrm{r}} H^{*}$ value through Eq. (3). As representatives, the EIS curves of $\mathrm{Ce}_{0.02}$ and $\mathrm{Ce}_{0.06}$ alloys milled for $30 \mathrm{~h}$ are illustrated in Fig. 13. Based on Eq. (3) and the data in EIS curves, the Kuriyama graphs of $\ln \left(T / R_{\mathrm{ct}}\right)$ versus $1 / T$ are established and inset in Fig. 13. The $\Delta_{\mathrm{r}} H^{*}$ value is able to be gotten expediently from the slopes of the fitting lines of Kuriyama plots. Figure 14 shows the changes of $\Delta_{\mathrm{r}} H^{*}$ value with Ce content and milling duration. Evidently, the $\Delta_{\mathrm{r}} H^{*}$ value descends at first and soon after ascends when increasing Ce content, and it drops with the prolongation of milling duration.

Comparing Figs. 9, 10 and 14, we found that the variation tendency of HRD value is similar with $D$ and contrary

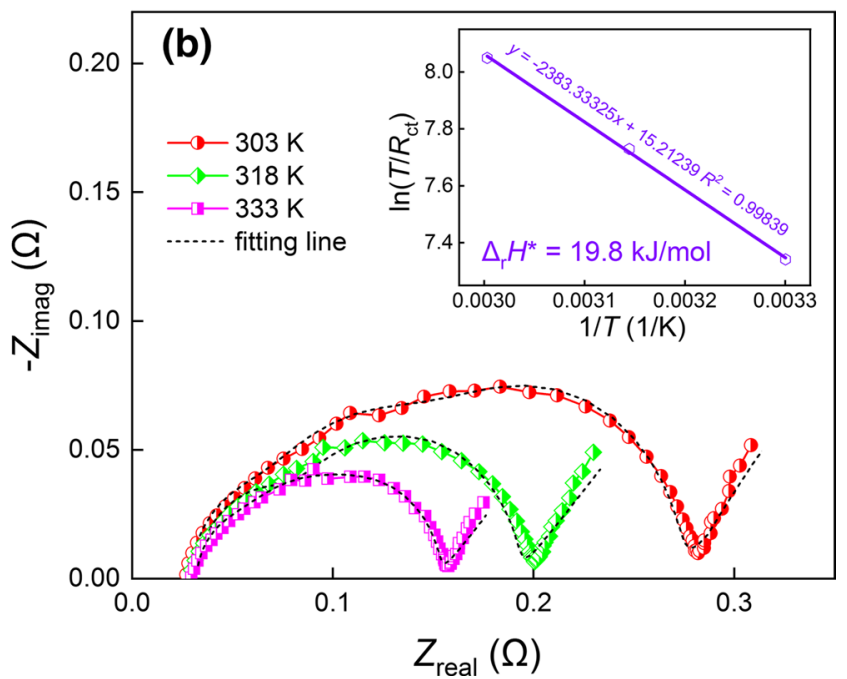

Fig. 13 Electrochemical impedance spectra (EIS) of as-milled $(30 \mathrm{~h}) \mathrm{Ce}_{0.02}$ and $\mathrm{Ce}_{0.06}$ alloys at various temperatures: a Ce $\mathrm{e}_{0.02}$ alloy, b Ce $\mathrm{e}_{0.06}$ alloy
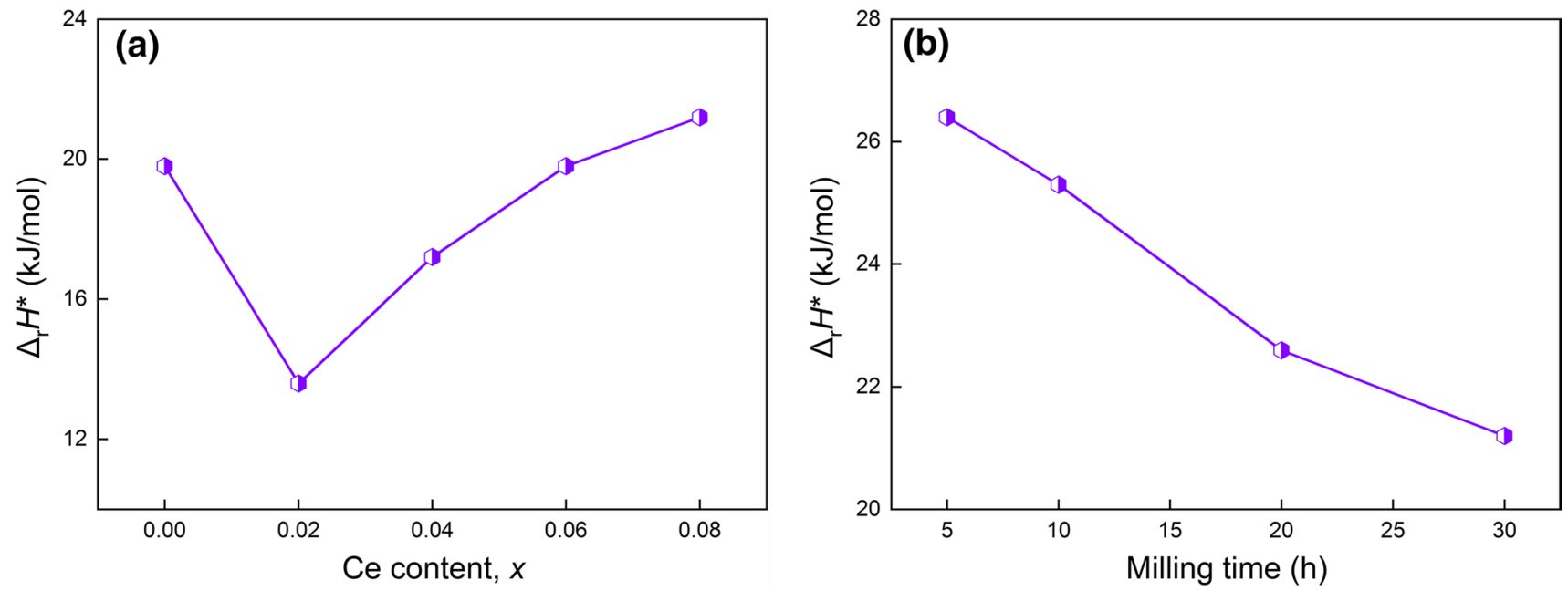

Fig. 14 Evolutions of the activation enthalpy $\Delta_{\mathrm{r}} H^{*}$ values of sample alloys: a as-milled $\mathrm{Mg}_{1-x} \mathrm{Ce}_{x} \mathrm{Ni}_{0.9} \mathrm{Al}_{0.1}(x=0-0.08)+50 \mathrm{Ni}$ alloys milled for $30 \mathrm{~h}, \mathbf{b ~ C e} \mathrm{Ce}_{0.08}$ alloy for different milled times 
to $\Delta_{\mathrm{r}} H^{*}$, which means the hydrogen diffusing coefficient and apparent activation enthalpy change have important implications on the high rate discharge ability of electrode. Based on the results in Figs. 10, 11 and 14, the substitution of $\mathrm{Ce}$ for $\mathrm{Mg}$ exerts both advantageous and pernicious effects on hydrogen diffusing coefficient and charge transferring rate, while ball milling exerts a positive impact. The positive contribution caused by substituting Mg with $\mathrm{Ce}$ is that adding Ce improves the alloy's corrosion resistance, which is beneficial for suppressing $\mathrm{Mg}$ from further oxidation and inducing a $\mathrm{Ni}$-enriched layer covering the alloy [18], thus improving the electrocatalytic activity of the electrode surface. The further increase in Ce content will consequentially result in the incrassation of $\mathrm{CeO}_{2}$ passivation layer, which forbids the hydrogen diffusing and charge transferring on the alloy surface. When prolonging milling duration, both the charge transferring rate and hydrogen diffusing rate improve, which mainly because the Ni coating layer possesses a high electrocatalytic activity. Moreover, the improved properties through mechanical milling are also related to the nano-/amorphous structure which accelerates both charge transferring and hydrogen diffusing and brings about a high electrochemical capacity [59]. The amount of interface and grain boundary increases with milling duration extending, which will produce many easy pathways for hydrogen atoms and elevate the absorption of hydrogen.

\section{Conclusions}

The microstructure characteristics and electrochemical performances of the as-milled $\mathrm{Mg}_{1-x} \mathrm{Ce}_{x} \mathrm{Ni}_{0.9} \mathrm{Al}_{0.1}$ $(x=0-0.08)+50 \mathrm{wt} \% \mathrm{Ni}$ alloys were investigated comprehensively in this study. The main conclusions can be summarized as follows.

1. A nanocrystalline and amorphous structure will appear in the experimental alloys after ball milling. The grain size of the as-cast alloys considerably shrinks with increasing Ce content.

2. The as-milled alloys display well electrochemical hydrogenation/dehydrogenation characteristics. The cycle stability and discharge capacity visibly improve with increasing milling time, while the discharge capacity shows a maximal value with increasing Ce content.

3. With Ce content growing, the electrochemical kinetics of alloys rises initially and cuts down subsequently, while it keeps growing with milling duration prolonging. The high rate discharge ability is mainly controlled by the hydrogen diffusing coefficient and apparent activation enthalpy change.
Acknowledgements This work was financially supported by the National Natural Science Foundations of China (Nos. 51761032 and 51871125).

\section{References}

[1] P. Dibandjo, C. Zlotea, R. Gadiou, C.M. Ghimbeu, F. Cuevas, M. Latroche, E. Leroy, C. Vix-Guterl, Int. J. Hydrog. Energy 38, 952 (2013)

[2] D. Mori, K. Hirose, Int. J. Hydrog. Energy 34, 4569 (2009)

[3] R. Lan, J.T.S. Irvine, S. Tao, Int. J. Hydrog. Energy 37, 1482 (2012)

[4] J. Wei, W. Chen, D. Chen, K. Yang, J. Mater. Sci. Technol. 34, 983 (2018)

[5] D. Chen, L. Chen, K. Yang, M. Tong, R. Long, W. Sun, Y. Li, J. Alloys Compd. 293-295, 724 (1999)

[6] K. Morimoto, I. Nagashima, M. Matsui, H. Maki, M. Mizuhata, J. Power Sources 388, 45 (2018)

[7] Y.C. Zhao, G.S. Huang, G.L. Gong, T.Z. Han, D.B. Xia, F.S. Pan, Acta Metall. Sin. (Engl. Lett.) 29, 1019 (2016)

[8] Z.W. Lu, S. Sun, G.R. Li, T.Y. Yan, J.Q. Qu, X.P. Gao, J. Alloys Compd. 433, 269 (2007)

[9] M. Anik, J. Alloys Compd. 486, 109 (2009)

[10] C. Rongeat, L. Roué, J. Power Sources 132, 302 (2004)

[11] X. Cai, F.S. Wei, F.N. Wei, H.H. Lu, Acta Metall. Sin. (Engl. Lett.) 29, 614 (2016)

[12] Y. Wang, W. Deng, X. Liu, S. Wang, X. Wang, Int. J. Hydrog. Energy 34, 1444 (2009)

[13] H. Yuan, Z. Zou, Z. Li, J. Ye, X. Guo, L. Jiang, S. Wang, X. Liu, Int. J. Hydrog. Energy 38, 7881 (2013)

[14] Z. Liu, Z. Hou, F. Ruan, Y. Yin, J. Zhang, J. Alloys Compd. 624, $68(2015)$

[15] Y.M. Li, B.Y. Duan, Z.C. Liu, Y.H. Zhang, H.P. Ren, Acta Metall. Sin. (Engl. Lett.) 31, 897 (2018)

[16] M.V. Simičić, M. Zdujić, R. Dimitrijević, L. Nikolić-Bujanović, N.H. Popović, J. Power Sources 158, 730 (2006)

[17] L.J. Huang, Y.X. Wang, J.G. Tang, Y.C. Zhao, G.F. Liu, Y. Wang, J.X. Liu, J.Q. Jiao, W. Wang, B. Jin, L.A. Belfiore, M.J. Kipper, J. Alloys Compd. 694, 1140 (2017)

[18] S. Ruggeri, L. Rouè, J. Huot, R. Schulz, L. Aymard, J.M. Tarascon, J. Power Sources 112, 547 (2002)

[19] Z. Dong, L. Ma, X. Shen, L. Wang, Y. Wu, L. Wang, Int. J. Hydrog. Energy 36, 893 (2011)

[20] J. Hao, S. Han, Y. Li, L. Hu, J. Zhang, J. Rare Earths 28, 290 (2010)

[21] Z.Y. Liu, X.L. Yan, N. Wang, Y.J. Chai, D.L. Hou, Int. J. Hydrog. Energy 36, 4370 (2011)

[22] Q.F. Tian, Y. Zhang, L.X. Sun, F. Xu, Z.C. Tan, H.T. Yuan, T. Zhang, J. Power Sources 158, 1463 (2006)

[23] Y. Zhang, F.S. Wei, J.N. Xiao, X. Cai, Acta Metall. Sin. (Engl. Lett.) 30, 1033 (2017)

[24] X. Yang, Y. Zhu, J. Zhang, Y. Zhang, Y. Liu, H. Lin, T. Wang, L. Li, J. Alloys Compd. 746, 421 (2018)

[25] S.F. Santos, J.F.R. Castro, T.T. Ishikawa, E.A. Ticianelli, J. Mater. Sci. 43, 2889 (2008)

[26] Q. Du, S. Li, G. Huang, Q. Feng, Int. J. Hydrog. Energy 42, 21871 (2017)

[27] H. Sun, D. Feng, Y. Zhang, H. Ren, Int. J. Hydrog. Energy 44, $5382(2019)$

[28] K.H. Young, T. Ouchi, L. Wang, D.F. Wong, J. Power Sources 279, 172 (2015)

[29] Y.H. Zhang, Y.Q. Li, H.W. Shang, Z.M. Yuan, T. Yang, S.H. Guo, J. Solid State Electrochem. 21, 1015 (2017) 
[30] Y.H. Zhang, H.P. Ren, B.W. Li, S.H. Guo, Q.C. Wang, X.L. Wang, Int. J. Hydrog. Energy 34, 6335 (2009)

[31] L.X. Wang, R.B. Song, C.H. Cai, J.Y. Li, Acta Metall. Sin. (Engl. Lett.) 32, 10 (2019)

[32] Y.Q. Liu, S.M. Han, L. Hu, B.Z. Liu, X. Zhao, Y.H. Jia, J. Rare Earths 31, 784 (2013)

[33] Y.P. Fan, B.Z. Liu, B.Q. Zhang, L.Q. Ji, Z. Zhang, J. Rare Earths 30, 1249 (2012)

[34] E.E. Levin, T.Y. Safonova, O.A. Petrii, J. New Mater. Electrochem. Syst. 9, 155 (2006)

[35] X. Liu, Z. Huang, L. Jiang, S. Wang, Int. J. Hydrog. Energy 32, 965 (2007)

[36] X. Zhao, Y. Ding, L. Ma, L. Wang, M. Yang, X. Shen, Int. J. Hydrog. Energy 33, 6727 (2008)

[37] W. Chen, Y. Zhu, C. Yang, J. Zhang, M. Li, L. Li, J. Power Sources 280, 132 (2015)

[38] M. Li, Y. Zhu, C. Yang, J. Zhang, W. Chen, L. Li, Int. J. Hydrog. Energy 40, 13949 (2015)

[39] L.S. Sun, J. Lin, Z.Y. Cao, F. Liang, L.M. Wang, J. Alloys Compd. 650, 15 (2015)

[40] X.H. Lu, T.Y. Liu, T. Zhai, G.M. Wang, M.H. Yu, S.L. Xie, Y.C. Ling, C.L. Liang, Y.X. Tong, Y. Li, Adv. Energy Mater. 4, 1300994 (2014)

[41] J.X. Zou, X.Q. Zeng, Y.J. Ying, X. Chen, H. Guo, S. Zhou, W.J. Ding, Int. J. Hydrog. Energy 38, 2337 (2013)

[42] J. Cui, J.W. Liu, H. Wang, L.Z. Ouyang, D.L. Sun, M. Zhu, X.D. Yao, J. Mater. Chem. A 2, 9645 (2014)

[43] C. Lu, J.X. Zou, X.Q. Zeng, W.J. Ding, Int. J. Hydrog. Energy 42, 15246 (2017)

[44] Y. Zhang, H. Wang, X. Dong, W. Bu, Z. Yuan, G. Zhang, Acta Metall. Sin. (Engl. Lett.) 27, 1088 (2014)
[45] M. Anik, J. Alloys Compd. 491, 565 (2010)

[46] X. Li, T. Yang, Y. Zhang, D. Zhao, H. Ren, Int. J. Hydrog. Energy 39, 13557 (2014)

[47] Y.H. Zhang, Z.M. Yuan, T. Yang, Z.H. Hou, D.L. Zhao, Acta Metall. Sin. (Engl. Lett.) 28, 826 (2015)

[48] Y. Wu, W. Han, S.X. Zhou, M.V. Lototsky, J.K. Solberg, V.A. Yartys, J. Alloys Compd. 466, 176 (2008)

[49] T. Spassov, L. Lyubenova, U. Köster, M.D. Baró, Mater. Sci. Eng. A 375-377, 794 (2004)

[50] Y. Ma, N. Li, D. Li, M. Zhang, X. Huang, J. Power Sources 196, 2346 (2011)

[51] V. Yartys, R. Denys, J. Alloys Compd. 645, S412 (2015)

[52] S. Orimo, H. Fujii, Appl. Phys. A 72, 167 (2001)

[53] M. Tliha, C. Khaldi, S. Boussami, N. Fenineche, O. El-Kedim, H. Mathlouthi, J. Lamloumi, J. Solid State Electrochem. 18, 577 (2014)

[54] A.A. Volodin, R.V. Denys, G.A. Tsirlina, B.P. Tarasov, M. Fichtner, V.A. Yartys, J. Alloys Compd. 645, S288 (2015)

[55] G. Zheng, B.N. Popov, R.E. White, J. Electrochem. Soc. 142, 2695 (1995)

[56] T.T. Zhai, T. Yang, Z.M. Yuan, Y.H. Zhang, Int. J. Hydrog. Energy 39, $14282(2014)$

[57] N. Kuriyama, T. Sakai, H. Miyamura, I. Uehara, H. Ishikawa, T. Iwasaki, J. Alloys Compd. 202, 183 (1993)

[58] H. Ding, S. Han, Y. Liu, J. Hao, Y. Li, J. Zhang, Int. J. Hydrog. Energy 34, 9402 (2009)

[59] T. Xiao, J. Yan, R.X. Duan, N. Gerile, Solid State Phenom. 271, 28 (2018) 